\title{
Imagery rescripting for the treatment of trauma in voice hearers: a case series
}

\author{
Georgie Paulik ${ }^{1,2}$, Craig Steel ${ }^{3}$ and Arnoud Arntz ${ }^{4, *}$ \\ ${ }^{1}$ Perth Voices Clinic, Murdoch, Western Australia, Australia, ${ }^{2}$ School of Psychological Science, University of Western \\ Australia, Perth, Western Australia, Australia, ${ }^{3}$ Oxford Institute of Clinical Psychology Training, Oxford University, \\ Oxford, UK and ${ }^{4}$ Department of Clinical Psychology, University of Amsterdam, Amsterdam, The Netherlands \\ *Corresponding author. Email: a.r.arntz@uva.nl
}

(Received 20 September 2018; revised 07 January 2019; accepted 25 January 2019; first published online 12 April 2019)

\begin{abstract}
Background: High rates of trauma and post-traumatic stress disorder (PTSD) are reported in people who hear voices (auditory hallucinations). A recent meta-analysis of trauma interventions in psychosis showed only small improvements in PSTD symptoms and voices. Imagery Rescripting (ImRs) may be a therapy that is more effective in this population because it generalizes over memories, which is ideal in this population with typically repeated traumas.

Aims: The primary aims of this study were to investigate whether ImR reduces (1) PTSD symptoms, and (2) voice frequency and distress in voice hearers.

Method: We used a single arm open trial study, case-series design. Twelve voice hearers with previous traumas that were thematically related to their voices participated. Brief weekly assessments (administered in sessions 1-8, post-intervention, and at 3-month follow-up) and longer measures (administered pre-, mid- and post-intervention) were administered. Mixed regression analysis was used to analyse the results.

Results: There was one treatment drop-out. Results of the weekly measure showed significant linear reductions over time in all three primary variables - voice distress, voice frequency, and trauma intrusions - all with large effect sizes. These effects were maintained (and continued to improve for trauma intrusions) at 3-month follow-up. On the full assessment tools, all measures showed improvement over time, with five outcomes showing significant time effects: trauma, voice frequency, voice distress, voice malevolence and stress.

Conclusions: The findings of the current study suggest that ImRs for PTSD symptoms is generally well tolerated and can be therapeutically beneficial among individuals who hear voices.
\end{abstract}

Keywords: auditory hallucinations; imagery rescripting; psychosis; PTSD; therapy; trauma; voices

\section{Introduction}

There has been a recent increase in the awareness of the high prevalence of traumatic life events experienced by people who have been diagnosed with a psychotic disorder, with approximately $75 \%$ reporting a trauma history, and $16-25 \%$ meeting criteria for post-traumatic stress (PTSD; Anketell et al., 2010; Brewin and Patel, 2010; de Bont et al., 2015; Hardy et al., 2016). The most established link within the literature is that between childhood sexual abuse and hearing voices (McCarthy-Jones and Longden, 2015). Voice-hearing is typically associated with a diagnosis of schizophrenia, with a lifetime prevalence of around two-thirds (McCarthy-Jones et al., 2017). However, the experience also occurs within people diagnosed with a range of other mental health

(C) British Association for Behavioural and Cognitive Psychotherapies 2019. This is an Open Access article, distributed under the terms of the Creative Commons Attribution licence (http://creativecommons.org/licenses/by/4.0/), which permits unrestricted re-use, distribution, and reproduction in any medium, provided the original work is properly cited. 
problems, including bipolar disorder, depression, personality disorders, post-traumatic stress disorder (PTSD) and dissociative identity disorder, as well as with individuals without a history of mental health problems (Aleman and Laroi, 2008).

Theoretical explanations of the link between traumatic life events and the onset of psychotic symptoms are mostly based on an underlying model of PTSD. Steel et al. (2005) describe how 'decontextualized' memories of traumatic events may be experienced in a manner which makes it difficult to identify these emotional and intrusive phenomena as a memory of a past event. Consequently, the individual may make sense of such an experience as something external and threatening (e.g. the Devil giving a warning). Similarly, the treatment of 'trauma symptoms' within psychosis has also been based on protocols developed for the treatment of PTSD. To date, two randomized controlled trials (RCTs) have been conducted in this area. Steel et al. (2017) report that a cognitive restructuring protocol was not effective in reducing PTSD symptoms within a 16-session, 6-month intervention. However, van den Berg et al. (2015) report that both prolonged exposure and eye movement desensitization and reprocessing (EMDR) were both effective in the treatment of PTSD in this group. However, subsequent analyses indicated that there was no effect on hearing voices (de Bont et al., 2016), an outcome supported when reviewing the outcomes of both of these trials together (Brand et al., 2018).

There are three important issues to consider at this point. First, exposure-based interventions may not be tolerated at a level sufficient to produce effects on voice hearing experiences. Of note, Keen et al. (2017) link the high drop-out rates seen when using prolonged exposure with psychosis to fear and avoidance of the reliving of traumatic memories. Second, exposure-based interventions may not work on the mechanisms which underlie the link between trauma symptoms and hearing voices [see Hardy (2017) for a discussion of a number of possible underlying mechanisms]. Third, most voice hearers who have suffered traumatic life events may not present with symptoms that are consistent with a diagnosis of PTSD. In line with this, Hardy et al. (2005) report that within a group of voice hearers who had reported a traumatic life event, only around $12 \%$ experienced voices in which the content had a direct match to the content of the trauma, whereas around $45 \%$ reported voices in which the emotional theme (e.g. humiliation) matched the emotion they experienced during the traumatic event. Thus many more voice hearers are 'trauma affected' than those diagnosed with PTSD.

Imagery rescripting (ImRs) is a technique aimed at modifying the meaning and emotions attached to a distressing memory (and thereby reducing wanted intrusions) by getting the individual to first imagine the start of the traumatic memory and then imaginally rewriting a new, safer ending with the aid of the therapist. ImRs has been shown to be effective in reducing PSTD symptoms (e.g. Alliger-Horn et al., 2015; Arntz et al., 2007; Ehlers et al., 2003; Grunert et al., 2007; Hackman, 2011; Smucker et al., 1995). There is also evidence for ImRs in reducing intrusive cognitions (i.e. images, nightmares, flashbacks, voices, thoughts) within a number of conditions, such as PTSD, social phobia, snake phobia, depression, obsessive compulsive disorder, body dysmorphic disorder, eating disorders and personality disorders (for literature review and meta-analysis, see Arntz, 2012; Morina et al., 2017). ImRs may be a more suitable form of trauma intervention than traditional exposure-based approaches in people who hear distressing voices. First, it does not entail the (prolonged) reliving of the highly distressing elements of traumatic memories (Arntz and Weertman, 1999), which is likely to relate to the fact that this approach has fewer drop-outs than exposure therapy (Arntz et al., 2013). Second, the ImRs process focuses on changing the meaning of a trauma, rather than focusing on the perceptual experience of any consequent intrusion. This would suggest that ImRs is better equipped to work with the interpersonal elements of childhood sexual abuse, which is prevalent within this group. This point is enhanced by the literature which suggests that the re-experiencing of intrusive memories may not be the main mechanism linking trauma with voice hearing experiences, and that mechanisms associated with the personal meaning and emotional theme of the traumatic event may be more important (Hardy, 2017; Hardy et al., 2005). Third, voice hearers have often suffered multiple 
traumas including childhood sexual abuse. The ImRs protocol requires fewer sessions to work on any one specific trauma, compared with prolonged exposure, and is therefore better suited to working with multiple traumas.

The only study to date using ImRs with voice hearers (Ison et al., 2014) was a small case series $(n=4)$ of a brief version (two sessions) of the intervention, which found a reduction in voice-related distress and negative affect, and that the approach was well tolerated. The current study reports on a naturalistic case-series study in which a non -diagnostic approach is taken to working with voice hearers using an ImRs (eight sessions) approach. The primary aims of this study are twofold: (1) to investigate whether imagery rescripting reduces PTSD symptoms, in particular intrusions, in a voice hearing sample; and (2) to investigate whether voice hearers report a reduction in voice frequency or distress following the ImRs treatment. Secondary aims were the following: (1) to explore the effects of the treatment on a range of other variables (depression, anxiety, self-esteem, beliefs about voices and social functioning), and (2) to get feedback from participants about the treatment to improve the application of ImRs for this specific population.

\section{Method}

\section{Service setting}

The data reported here are taken from clients attending Perth Voices Clinic (PVC) for therapy to work on trauma and voices. PVC is a transdiagnostic psychological assessment, treatment and research clinic for people who experience auditory and other hallucinatory experiences. Ethical approval was obtained by the Murdoch University Human Research Ethics Committee (reference no. 2016/089), and all participants gave written informed consent for their de-identified clinical data to be published.

\section{Design}

A single arm open trial study, case-series design, was used with weekly assessments (administered at sessions 1-8, post-intervention, and at 3-month follow-up) for a set of brief measures and three assessment points: pre-intervention, mid-intervention and post-intervention for longer measures.

\section{Participants}

Twelve participants commenced Imagery Rescripting at PVC between February 2017 and March 2018. Given that this was a naturalistic study, participants commenced therapy as they were referred to the clinic and were deemed suitable (meeting intake criteria) for the ImRs intervention on assessment. The mean length of treatment (from pre-treatment assessment to post-treatment assessment) was 11.75 weeks ( $S D=2.90$, range 9-19). There were no participants specifically referred for the ImRs intervention at PVC that were deemed not suitable. Participants were considered eligible if they (a) presented at PVC and were currently hearing voices, (b) provided informed participant consent, and (c) suffered a trauma (any event which the individual endured and caused significant distress) and seemed to experience PTSD symptoms that were regarded by the client and therapist to be either directly or indirectly related to their experience of hearing voices (n.b. having a current PTSD diagnosis was not an inclusion criteria and there was no symptom threshold employed). A direct relationship between trauma and the voices is where the content of the trauma corresponds to the content of the voice (i.e. the voice says the exact things a perpetrator previously said) (Hardy et al., 2005). An indirect relationship between trauma and the voices is where the themes of the trauma correspond to the themes of the voice (i.e. someone who was bullied at school or home hears critical voices) (Hardy et al., 2005). Exclusion criteria for PVC includes being in an acute phase of psychosis, or having residual delusions or thought disorder impairing their ability to engage in therapy (as indicated by a score of 5 or above on either the Unusual Thought Content or Conceptual Disorganization items of the Brief Psychiatric Rating 
Scale; Ventura et al., 1993). Average age of participants was 41 years (range 20-62, SD 13.4), nine (75\%) were female, and the average duration of hearing voices was 19.75 years (range 1-42, $S D$ 13.30). Nine of the participants had a schizophrenia spectrum disorder and all used medication (see Table 1 for more details). The type of relationship between trauma and voice hearing experience (and other demographic information) for each client is presented in Table 1.

One participant completed only four rescripting sessions and then withdrew from therapy stating her reason for this as 'I feel I have made enough gains to enjoy life' and that she had just commenced a new job so had limited time. She was still happy to complete the 3-month follow-up assessment. We have classified this client as 'treatment drop-out'.

\section{Measures}

Primary outcomes

Trauma intrusions. Trauma intrusions were assessed weekly (at the start of each session) and at 3-month follow-up by obtaining a retrospective self-reported total number of trauma-related intrusions (i.e. nightmares and flashbacks of any traumatic memory, irrespective of whether they were addressed in the rescripting therapeutic work) experienced in the past week.

PTSD-severity. At baseline, mid-treatment and post-treatment the Post-traumatic Symptom Scale - Part B (PSS; Foa et al., 1993) was administered to assess PTSD symptom severity. The PSS is a 17-item self-report questionnaire measuring PTSD symptoms of re-experiencing, avoidance and arousal. Respondents rate the frequency of symptoms on a 5-point scale $(0=$ not at all, $4=$ five or more times per week/almost always). The PSS has demonstrated good construct validity, internal consistency, and test-retest reliability (Cronbach's $\alpha=.91$; Foa et al., 1993). The total score constituted the measure of PSTD severity.

Voice frequency and distress. Two single items on voices were obtained weekly during therapy and at 3-month follow-up: (1) frequency (0-6, where $0=$ 'not present', $6=$ 'continuous'); and (2) average voice-related distress (0-10, where 10 is the maximum distress). The Psychotic Symptom Rating Scales - Auditory Hallucinations (PSYRATS-AH; Haddock et al., 1999) was administered at pre-, mid- and post-therapy, and is an 11-item semi-structured interview assessing multiple aspects of the hearing voices experience. The distress (items 6, 7, 8, 9 and 11) and severity (items 1, 2 and 10) subscales were used as primary outcomes. Woodward et al. (2014) reported high intraclass correlation coefficients of 0.93 for distress, and 0.87 for frequency subscales.

\section{Secondary outcomes}

Depression Anxiety and Stress Scale-21 (DASS; Lovibond and Lovibond, 1995). This is a 21 -item self-report questionnaire assessing affect and distress, providing a score for depression, anxiety and stress. Each item is rated on a $0-3$ scale $(0=$ do not apply to me at all, $3=$ applied to me very much/most of the time, over the past week). The DASS-21 has demonstrated excellent internal consistency and concurrent validity (Antony et al., 1998) and adequate construct validity (Henry and Crawford, 2005).

Rosenberg Self-Esteem Scale (RSES; Rosenberg, 1965). This is a 10-item self-report questionnaire assessing self-worth and self-esteem. Responses on the scale were measured on a 5-point Likert scale ( $1=$ strongly agree, $5=$ strongly disagree). The RSES shows excellent internal consistency and test-retest reliability (Rosenberg, 1965).

Beliefs About Voices Questionnaire-Revised (BAVQ-R; Chadwick et al., 2000). Only the 12 self-report items from the Omnipotence and Malevolence subscales were administered to reduce participant burden. These subscales have been shown to demonstrate good validity and reliability (Cronbach's $\alpha=0.84$ and 0.74 , respectively).

Social and Occupational Functioning Assessment Scale (SOFAS; Goldman et al., 1992). This is a single item clinician rating of a client's current functioning level. The clinician rates the client's functioning on a scale of $1-100$, where $1=$ 'Persistent inability to maintain minimal personal 
Table 1. Participant demographic and clinical information

\begin{tabular}{|c|c|c|c|c|c|c|}
\hline $\begin{array}{l}\text { Participant } \\
\text { number and } \\
\text { diagnosis }{ }^{\star}\end{array}$ & Gender & Age & Age of voice onset* & Medication* & Trauma-voice association & Additional comments \\
\hline $\begin{array}{l}1 \\
\text { Major } \\
\quad \text { depressive } \\
\text { disorder; } \\
\text { generalized } \\
\text { anxiety } \\
\text { disorder }\end{array}$ & $\mathrm{F}$ & 27 & 1 & $\begin{array}{l}\text { Escitalopram } 5 \mathrm{mg} \\
\text { (anti-depressant) }\end{array}$ & $\begin{array}{l}\text { Indirect. Trauma - severe } \\
\text { emotional and physical } \\
\text { neglect and isolation in early } \\
\text { childhood. From pre-verbal } \\
\text { age she started hearing a } \\
\text { group of voices that would } \\
\text { comment and discuss things } \\
\text { she was doing/thinking, to } \\
\text { 'keep me company' }\end{array}$ & $\begin{array}{l}\text { Low rates of current PTSD } \\
\text { symptoms (i.e. flashbacks and } \\
\text { nightmares), although had } \\
\text { regular memories of the } \\
\text { trauma, which reduced with } \\
\text { therapy but was not captured } \\
\text { in the data }\end{array}$ \\
\hline $\begin{array}{l}2 \\
\text { Major } \\
\quad \text { depressive } \\
\text { disorder; PTSD }\end{array}$ & $\mathrm{F}$ & 30 & 19 & $\begin{array}{l}\text { Quetiapine } 300 \mathrm{mg} \\
\text { (anti-psychotic) }\end{array}$ & $\begin{array}{l}\text { Indirect. Trauma - severe } \\
\text { prolonged childhood sexual } \\
\text { abuse by stepfather. Two } \\
\text { male voices threating her and } \\
\text { telling her to kill herself }\end{array}$ & $\begin{array}{l}\text { High levels of dissociation were } \\
\text { an initial difficulty in } \\
\text { rescripting, although } \\
\text { grounding techniques helped } \\
\text { to keep the client present }\end{array}$ \\
\hline $\begin{array}{l}3 \\
\text { Personality } \\
\quad \text { disorder; } \\
\text { schizophrenia }\end{array}$ & $\mathrm{F}$ & 42 & 5 & $\begin{array}{l}\text { Venlafaxine } 150 \mathrm{mg} \\
\text { (anti-depressant), } \\
\text { apiprazole } 20 \mathrm{mg} \\
\text { (anti-psychotic), } \\
\text { temazepam } 10 \mathrm{mg} \\
\text { (benzodiazepine), } \\
\text { clonazepam } 2 \mathrm{mg} \\
\text { (anti-convulsant) }\end{array}$ & $\begin{array}{l}\text { Direct and indirect. Trauma - } \\
\text { being bullied at home } \\
\text { (especially by father) and at } \\
\text { school. Voices took the } \\
\text { identity of people who had } \\
\text { bullied her in the past and } \\
\text { said similar things }\end{array}$ & \\
\hline $\begin{array}{l}4 \\
\text { Schizophrenia }\end{array}$ & M & 60 & 18 & $\begin{array}{l}\text { Zuclopenthixol } 5 \mathrm{mg} \\
\text { (anti-psychotic) }\end{array}$ & $\begin{array}{l}\text { Indirect. Trauma - complex } \\
\text { childhood trauma with a large } \\
\text { range of different types of } \\
\text { childhood traumas, including } \\
\text { victim of violence, neglect, } \\
\text { sexual abuse, and witnessing } \\
\text { several loved ones die. His } \\
\text { voices continually threatened } \\
\text { him and his family's safety, } \\
\text { telling him they were coming } \\
\text { to get him/them }\end{array}$ & $\begin{array}{l}\text { This participant rated on the } \\
\text { TALE that he did not believe } \\
\text { his past trauma was impacting } \\
\text { on his current life; however, } \\
\text { he and the therapist could see } \\
\text { the strong thematic and } \\
\text { emotional link between his } \\
\text { trauma and voices }\end{array}$ \\
\hline
\end{tabular}


Table 1. (Continued)

\begin{tabular}{|c|c|c|c|c|c|c|}
\hline $\begin{array}{l}\text { Participant } \\
\text { number and } \\
\text { diagnosis }^{\star}\end{array}$ & Gender & Age & Age of voice onset ${ }^{\star}$ & Medication* & Trauma-voice association & Additional comments \\
\hline $\begin{array}{l}5 \\
\text { Schizophrenia; } \\
\quad \text { major } \\
\text { depressive } \\
\text { disorder }\end{array}$ & M & 40 & 17 & $\begin{array}{l}\text { Apiprazole } 5 \mathrm{mg} \\
\text { (anti-psychotoic), } \\
\text { lamotrigine } 200 \mathrm{mg} \\
\text { (anti-convulsant), } \\
\text { sertraline } 300 \mathrm{mg} \text { (anti- } \\
\text { depressant), melatonin }\end{array}$ & $\begin{array}{l}\text { Indirect. Trauma - physical and } \\
\text { emotional abuse by father. His } \\
\text { voices threaten him and } \\
\text { criticize him }\end{array}$ & $\begin{array}{l}\text { Very low rates of PTSD } \\
\text { symptoms at baseline, } \\
\text { although was having frequent } \\
\text { and distressing intrusive } \\
\text { images related to his trauma } \\
\text { (but not of the trauma) which } \\
\text { stopped altogether by the end } \\
\text { of ImRs which is not captured } \\
\text { in the data }\end{array}$ \\
\hline $\begin{array}{l}6 \\
\text { Major } \\
\quad \text { depressive } \\
\text { disorder; PTSD }\end{array}$ & $\mathrm{F}$ & 29 & 24 & $\begin{array}{l}\text { Desvenlafaxine } 100 \mathrm{mg} \\
\text { (anti-depressant) }\end{array}$ & $\begin{array}{l}\text { Direct. Trauma - repeat } \\
\text { childhood sexual abuse by } 3 \\
\text { different perpetrators. } \\
\text { Additional traumas also of car } \\
\text { accident and finding a friend } \\
\text { dead. She heard the voice of } \\
\text { one of the perpetrators, who } \\
\text { would say the same } \\
\text { grooming-related words to } \\
\text { her, and she could feel breath } \\
\text { on her neck }\end{array}$ & $\begin{array}{l}\text { This client reported hearing the } \\
\text { voice only once in the week } \\
\text { post-treatment and then said } \\
\text { it stopped altogether the week } \\
\text { following }\end{array}$ \\
\hline $\begin{array}{l}7 \\
\text { Schizophrenia; } \\
\quad \text { PTSD }\end{array}$ & $\mathrm{F}$ & 54 & 21 & $\begin{array}{l}\text { Sodium valproate (mood } \\
\text { stabilizer) } 200 \mathrm{mg}, 500 \\
\text { mg; venlafaxine (anti- } \\
\text { depressant) } 150 \mathrm{mg} ; \\
\text { aripiprazole (anti- } \\
\text { psychotic) } 20 \mathrm{mg} ; \\
\text { mirtazapine } \\
\text { (anti-depressant) } 30 \mathrm{mg} \text {; } \\
\text { quetiapine } \\
\text { (anti-psychotic) } 150 \mathrm{mg}\end{array}$ & $\begin{array}{l}\text { Direct and indirect. Trauma - } \\
\text { childhood neglect and sexual } \\
\text { abuse. The identity of the } \\
\text { voices was the abuser, but the } \\
\text { content was indirectly related } \\
\text { to her traumas, with the voice } \\
\text { commanding her to hurt or } \\
\text { kill herself }\end{array}$ & $\begin{array}{l}\text { Major life stressors occurred } \\
\text { towards the end of therapy. } \\
\text { Only completed } 5 / 7 \text { rescripts } \\
\text { because of this. The client did } \\
\text { not complete the 3-month } \\
\text { follow-up assessment as they } \\
\text { changed their address and } \\
\text { number }\end{array}$ \\
\hline
\end{tabular}


Table 1. (Continued)

\begin{tabular}{|c|c|c|c|c|c|c|}
\hline $\begin{array}{l}\text { Participant } \\
\text { number and } \\
\text { diagnosis }^{\star}\end{array}$ & Gender & Age & Age of voice onset ${ }^{\star}$ & Medication* & Trauma-voice association & Additional comments \\
\hline $\begin{array}{l}8 \\
\text { Schizophrenia; } \\
\quad \text { major } \\
\text { depressive } \\
\text { disorder; } \\
\quad \text { generalized } \\
\text { anxiety } \\
\text { disorder }\end{array}$ & $\mathrm{F}$ & 40 & 18 & $\begin{array}{l}\text { Aripiprazole (anti- } \\
\text { psychotic) } 20 \mathrm{mg} ; \\
\text { desvenlafaxine } \\
\text { (anti-depressant) } 100 \\
\text { mg; lurasidone } \\
\text { hydrochloride (anti- } \\
\text { psychotic) } 80 \mathrm{mg} ; \\
\text { olanzapine (anti- } \\
\text { psychotic) } 10 \mathrm{mg} \text {; } \\
\text { clonazepam } \\
\text { (anti-convulsant) } 0.5 \mathrm{mg}\end{array}$ & $\begin{array}{l}\text { Indirect. Trauma - physical and } \\
\text { emotional abuse by father; } \\
\text { bullied at school (teachers } \\
\text { and pupils) and work; two } \\
\text { accounts of sexual abuse in } \\
\text { her twenties. Her voices say } \\
\text { similar things to previous } \\
\text { people who have bullied her }\end{array}$ & $\begin{array}{l}\text { Withdrew after } 4 \text { rescripts - } \\
\text { stating her reasons as 'I feel I } \\
\text { have made enough gains to } \\
\text { enjoy life' and that she no } \\
\text { longer had enough time, } \\
\text { having started a new job. She } \\
\text { still completed the } \\
\text { 3-month follow-up assessment }\end{array}$ \\
\hline $\begin{array}{l}9 \\
\text { PTSD; } \\
\quad \text { schizoaffective } \\
\quad \text { disorder }\end{array}$ & $M$ & 39 & 19 & $\begin{array}{l}\text { Aripiprazole (anti- } \\
\text { psychotic) } 15 \mathrm{mg}, \\
\text { clozapine } 400 \mathrm{mg} \text { (anti- } \\
\text { psychotic), escitalopram } \\
20 \mathrm{mg} \text { (anti-depressant), } \\
\text { lamotrigine } 100 \mathrm{mg} \\
\text { (anti-convulsant) }\end{array}$ & $\begin{array}{l}\text { Direct and indirect. Trauma - } \\
\text { physical, emotional and sexual } \\
\text { abuse at home during } \\
\text { childhood. His voice was of } \\
\text { his perpetrator, although it } \\
\text { would also say things both } \\
\text { directly and indirectly related } \\
\text { to his trauma history }\end{array}$ & $\begin{array}{l}\text { The client reported frequent and } \\
\text { distressing intrusive images } \\
\text { related to his trauma (but not } \\
\text { of the trauma) which } \\
\text { significantly reduced by the } \\
\text { end of ImRs which is not } \\
\text { captured in the data }\end{array}$ \\
\hline $\begin{array}{l}10 \\
\text { PSTD, possible } \\
\text { schizophrenia }\end{array}$ & $\mathrm{F}$ & 62 & 61 & $\begin{array}{l}\text { Quetiapine (anti-psychotic) } \\
75 \mathrm{mg} \text {; amisulpride } \\
\text { (anti-psychotic) } 300 \mathrm{mg}\end{array}$ & $\begin{array}{l}\text { Indirect. Trauma - finding her } \\
\text { brother's body (suicide). Her } \\
\text { voices commenced within } \\
\text { weeks of his death and tell } \\
\text { her to also kill herself }\end{array}$ & $\begin{array}{l}\text { Client only completed } 6 / 7 \\
\text { rescripts because client and } \\
\text { therapist agreed she had met } \\
\text { her goals (no longer having } \\
\text { any nightmares or flashbacks) }\end{array}$ \\
\hline $\begin{array}{l}11 \\
\text { Schizoaffective } \\
\quad \text { disorder }\end{array}$ & $\mathrm{F}$ & 20 & 8 & $\begin{array}{l}\text { Brexpiprazole (anti- } \\
\text { psychotic) } 6 \mathrm{mg} \text {; lithium } \\
\text { carbonate (mood } \\
\text { stabilizer) } 500 \mathrm{mg} \text {; } \\
\text { amitriptyline (anti- } \\
\text { depressant) } 75 \mathrm{mg}\end{array}$ & $\begin{array}{l}\text { Indirect. Trauma - bullying at } \\
\text { home and at school and } \\
\text { sexual assault in adulthood. } \\
\text { Her voices are critical and } \\
\text { bully her. The voices said the } \\
\text { same thigs her dad used to } \\
\text { say to her (i.e. 'you're useless') }\end{array}$ & $\begin{array}{l}\text { Several medication changes early } \\
\text { on in therapy and some } \\
\text { additional stressors (i.e. } \\
\text { moving house) towards the } \\
\text { end. Only completed } 5 / 7 \\
\text { rescripts because of these } \\
\text { disruptions }\end{array}$ \\
\hline $\begin{array}{l}12 \\
\text { Schizophrenia }\end{array}$ & $\mathrm{F}$ & 51 & 46 & $\begin{array}{l}\text { Quetiapine (anti-psychotic) } \\
75 \mathrm{mg} \text {; amisulpride } \\
\text { (anti-psychotic) } 300 \mathrm{mg}\end{array}$ & $\begin{array}{l}\text { Indirect. Trauma - her daughter } \\
\text { screaming in distress during } \\
\text { the year before her death. Her } \\
\text { voices tell her she has killed } \\
\text { the young (male) voice she } \\
\text { hears }\end{array}$ & $\begin{array}{l}\text { Client only completed } 5 / 7 \\
\text { rescripts because client and } \\
\text { therapist agreed she had met } \\
\text { her goals (no longer having } \\
\text { any nightmares or flashbacks) }\end{array}$ \\
\hline
\end{tabular}


hygiene. Unable to function without harming self or others or without considerable external support' and $100=$ 'Superior functioning in a wide range of activities'. The SOFAS has demonstrated good inter-rater reliability and construct validity (Hilsenroth et al., 2000).

\section{Additional measures}

Trauma and Life Events Checklist (TALE; Carr et al., 2016). This measure was used at baseline only to record the type and age of traumas the client had experienced.

Qualitative feedback. Participants were asked if they had any feedback on how they found the therapy and their responses were taken down verbatim.

\section{Procedure}

Participants were assessed at three different time points on all measures as part of the routine outcome assessments: (1) pre-therapy; (2) mid-therapy - completed during the fifth therapy session; and (3) Ppost-therapy - 1 week after the final rescripting therapy session. Weekly measures were administered every therapy session, post-therapy, and at 3-months follow-up (obtained by telephone). Because this case series was conducted as part of routine service delivery (without research funding), assessment measures were delivered by the therapist (author G.P.).

The number of therapy sessions was chosen based on the national funding model for clinical psychology in private practice in Australia (Medicare), which funds 10 sessions per year, used for assessment ( 1 session), therapy (8 sessions) and wrap-up (1 session). At baseline participants underwent a psychological assessment of their current and previous mental health (focusing primarily on their experience of voices), and of their trauma history. There were eight active therapy sessions. The first focused primarily on psychoeducation and preparation. It included developing a plan of which traumatic memories to rescript and in which order, a practice re-script of a slightly negative childhood memory and a practice of the visualization homework ${ }^{1}$ task of imagining soothing their child-self (details available on request). The next seven sessions entailed one rescript per session (detail below; therapy protocol available on request). Therapy ended with a wrap-up session, which included completing the final assessment measures (questionnaires completed in the waiting area), feedback and a discussion about relapse prevention and future goals.

\section{Rescripting procedure}

All participants reported multiple traumas, either several different types/clusters of traumatic events or a single type experienced multiple times (i.e. repeat sexual abuse). The patient and therapist determined together which traumas to address in what order. Typically, more severe traumas and earlier traumas were completed first. In addition, the thematic and emotional links between their voices and memories was explored with the therapist and where there was a clear link, these memories would be rescripted. For several clients, where it was less clear which traumas were most related to their voices, the therapist would get the client to imagine a recent distressing event of voice hearing and use this as an emotional bridge to help select which memory to rescript in that session. The rescripting procedure was primarily pre-emptive, in that the client and therapist would agree on which trauma to work on and where in the memory the rescripting would commence. There were three single instances where an emotional bridge was used to elicit a memory, during which the client was instructed to close their eyes and recall a recent distressing voice experience and then asked to sit with the provoked emotion until a childhood memory came to mind. Then the rescript would commence, with the therapist asking 'would it be ok for me to enter now?' when they suspected the trauma was about to take place. Typically, however, when rescripting a childhood memory, the participant closes their eyes and goes back to the beginning

\footnotetext{
${ }^{1}$ This homework task was given as a suggested way to continue imagery work at home on the last (post-therapy) session for participants 1 to 4 . Their feedback was that they would have liked it earlier in therapy, and so this was introduced in session 1 or 2 for all other participants.
} 
Box 1: Case illustration

Amy experienced prolonged periods of social isolation and neglect from a very young age. From a pre-verbal age she started hearing voices that would discuss things she was doing or thinking, to 'keep me company'. Amy and her therapist could see an indirect link between the trauma (neglect) and the voices: they provided her with companionship, and when she would feel distressed, they would say the word 'home' (which evoked sadness).

Amy's third rescript was of a memory at age 5 when she was in her bedroom playing with her dolls alone. The therapist guided the first half of the rescript, and in the second half would ask Amy what she felt she needed at that specific time in the memory and then upon her response say something like 'ok, go ahead and tell me what is happening now'. In order to relive the memory, the therapist guided Amy to relax, then close her eyes and go back to being her 5-year-old self sitting in her bedroom.

Pausing the memory, the therapist entered the image at the point where Amy felt fearful and alone, and sat with Amy on the floor. She assured Amy that she was safe, and that she [the therapist] would ensure that she was not left alone ever again. She [the therapist] then called her parents and told them they must come home and while they waited, they played together. When the parents arrived the therapist again assured Amy she was safe, then stood and sternly spoke to the parents about their inexcusable behaviour. She spoke about how Amy's needs were not being met and needed her parents' love and devotion. The parents looked ashamed, upset and apologetic when they looked at Amy. The parents assured the therapist and Amy that they would do better and her dad gave her a hug. The therapist said she would be doing daily checks and gave Amy a magic teleport device so that Amy could teleport her [therapist] if her parents ever broke their promise or she felt unsafe. The therapist then took Amy across the road to the park to play with other children (her request) and reassured her that she would be watching. After playing, Amy then went home hand-in-hand with the therapist to find her parents in the kitchen cooking her favourite dinner. Her mum gave her a hug and said she would take her to the park tomorrow to play again. Amy was teary throughout the rescript but said she felt calm and soothed, though sad, after the rescript. The next week Amy reported feeling more supported and less stressed by her voices.

of the chosen traumatic memory. The therapist asks questions to help ground the participant in that memory, such as 'what can you see/hear/feel/think...', and then asks them 'what is happening now?'. Right before the traumatic event commences (i.e. when a violent parent raises their hand to hit the child) the therapist enters the image and takes control of what happens next ('rescripts') until all the child's needs are met and the client is feeling calm and safe. As the therapy progresses, the client is given more control over how their needs are met - the therapist asks 'what do you need?' and then gets the client to describe what is happening now. In the final few sessions (if the client is considered ready), the adult client (their current self) entered the memory, instead of the therapist, and helped get their younger-self needs met, after which the rescript was repeated with the child-self viewing the adult-self help them get their needs met (Arntz and Weertman, 1999).

\section{Statistical analysis}

We conducted intent-to-treat analyses by using (generalized) linear mixed models [(G)LMM], thus all available data were used in the analysis. Changes in outcome measures over time were analysed by SPSS24 LMM (in case the distribution was not normal, GLMM with an appropriate distribution, e.g. negative binomial for skewed data). For the three measures that were taken each session (voice distress, voice frequency, intrusions) AR1 and ARMA11 were considered for the repeated part, and the covariance structure with the best fit was chosen. For the measures that 
were taken at pre-, mid- and post-test, an unstructured covariance structure was used. The time effect was represented by a linear trend starting at zero (i.e. with the session-by-session measures, time was represented by $0,1,2,3 \ldots$; for the other outcomes time was represented by $0,1,2$ ). A quadratic trend for time was explored by adding a centred quadratic time effect. As it failed to reach significance, quadratic effects were left out of the final analyses and not reported. For the session-by-session outcomes, random intercept and slope were added if estimation allowed. Residuals were inspected to check for outliers and whether they fitted the normality assumption. Analyses were repeated without outliers to check robustness of the initial analysis. The Results section reports the linear time effects. As effect sizes, we report $r$, defined as $r=t / \sqrt{ }\left(t^{2}+\right.$ d.f.), representing the effect size of the linear time effect in the fixed part of the linear mixed models analysis. We also report conventional Cohen's $d$ as the mean difference between first and last observation of the active period (mostly post-test), and between first and follow-up observation, divided by the pretest $S D$.

For analysing the 3-month follow-up assessments a piecewise regression model was used: the slope of time during treatment was separately estimated from the slope from last session to 3-months follow-up. Thus the model had two fixed predictors: time and a dummy for follow-up. The time variable was recoded to $(-8,-7, \ldots, 0)$ so that the intercept (time $=0)$ was at session 10. The follow-up was also coded time $=0$. The slope from session 10 to follow-up was represented with a dummy $(0,1)$ so that the coefficient of this dummy represents the change from session 10 to follow-up.

\section{Results}

\section{Descriptive statistics}

Twelve clients commenced ImRs as part of this case series. One participant (participant 8) decided to end therapy at the mid-therapy time point, although the participant completed the follow-up measures. Two other clients completed therapy 1 week (participant 10) and 2 weeks (participant 12) early because client and therapist both agreed therapy goals had been achieved (therefore not considered to be treatment drop-outs). The descriptive statistics for the primary and secondary measures administered at pre-, mid- and post-therapy are reported in Table 2.

\section{Session-by-session outcomes}

Voice distress and intrusions showed skewed distributions, and were therefore analysed with GLMM negative binomial regression with a log-link, voice distress after inverting and doubling the scores to produce integer values only that were skewed to the right (negative binomial regression only handles integers $\geq 0$ ). Results showed significant linear reductions over time in voice distress, voice frequency and intrusions, with large effect sizes (see Table 3 and Figs 1 and 2; and for means and standard deviations see Table 5 in the Supplementary Material). Analyses were repeated with outliers left out. Results were robust. Therefore the results of the initial analyses are reported.

\section{Outcomes assessed at pre-, mid- and post-test}

All outcome measures showed improvement over time, with five outcomes showing significant time effects (Table 4). More specifically, the primary outcomes (PSS total, PSYRATS-AH Frequency and PSYRATS-AH Distress) showed large improvements (see Table 2). While there were no significant improvements on DASS Depression and Anxiety, the DASS Stress subscale showed a significant reduction. Self-esteem as assessed with the RSES did not improve significantly. The BAVQ subscales showed skewed distributions to the left, thus inverted scores 
Table 2. Means and standard deviations (SD) on clinical assessment measures pre-therapy, mid-therapy (session 5) and post-therapy $(n=12)$

\begin{tabular}{|c|c|c|c|c|c|c|c|}
\hline & \multicolumn{2}{|c|}{ Pre-therapy } & \multicolumn{2}{|c|}{ Mid-therapy } & \multicolumn{2}{|c|}{ Post-therapy } & \multirow[b]{2}{*}{$d$} \\
\hline & Mean & $S D$ & Mean & $S D$ & Mean & $S D$ & \\
\hline PSS total & 29 & 14.35 & 24 & 14.50 & 18 & 10.95 & 0.80 \\
\hline PSYRATS-AH Distress & 16 & 5.61 & 13 & 5.79 & 12 & 5.95 & 0.74 \\
\hline PSYRATS-AH Severity & 9 & 2.90 & 7 & 2.60 & 6 & 2.54 & 0.80 \\
\hline DASS Depression & 17.75 & 10.15 & 17 & 10.99 & 15 & 11.89 & 0.26 \\
\hline DASS Anxiety & 17 & 12.08 & 16 & 12.30 & 16 & 9.72 & 0.14 \\
\hline DASS Stress & 22 & 13.65 & 19 & 11.17 & 17 & 10.88 & 0.33 \\
\hline RSES* & 15 & 7.40 & 17 & 9.42 & 17 & 8.56 & 0.25 \\
\hline BAVQ (Malevolence) & 9 & 5.04 & 9 & 4.94 & 8 & 5.20 & 0.37 \\
\hline BAVQ (Omnipotence) & 11 & 4.59 & 11 & 5.02 & 10 & 4.55 & 0.24 \\
\hline SOFAS* & 54 & 21.02 & 63 & 20.04 & 65 & 21.83 & 0.49 \\
\hline
\end{tabular}

*Higher scores are indicative of better outcomes. Cohen's $d=$ change pre-post divided by pre SD. PSS, Posttraumatic Symptom Scale; PSYRATSAH, Psychotic Symptom Rating Scales - Auditory Hallucinations; DASS, Depression Anxiety and Stress Scale-21; RSES, Rosenberg Self-Esteem Scale; BVAQ, Beliefs About Voices Questionnaire-Revised; SOFAS, Social and Occupational Functioning Assessment Scale.

Table 3. Session-by-session measures: linear trends estimated by linear mixed model analysis

\begin{tabular}{lcccccccc}
\hline & & & & & & \multicolumn{2}{c}{$95 \% \mathrm{Cl}$} \\
\cline { 5 - 8 } & $\beta$ & s.e. & d.f. & $t$ & $p$ & Lower & Upper & $r$ \\
\hline Voice distress $^{1,2}$ & .07 & .02 & 23 & 3.19 & .004 & 1.03 & 1.12 & .55 \\
Voice frequency $^{3}$ & -.09 & .03 & 17.04 & -2.71 & .015 & -.17 & -.02 & .55 \\
Intrusions $^{1}$ & -.25 & .06 & 28 & -4.01 & $<.001$ & -.37 & -.13 & .60 \\
\hline
\end{tabular}

Time coded $0,1,2, \ldots$. Analysed with ARMA11 covariance structure for the repeated part and for voice frequency a random intercept. For voice distress and intrusions no random part was added as this caused estimation problems. Effect size $r=t / \mathrm{SQRT}\left(t^{2}+\mathrm{d} . \mathrm{f}.\right)$. ${ }^{1}$ Generalized linear mixed model (binomial distribution with log-link) because of skewed distribution. Parameters are in transformed scale. ${ }^{2}$ Voice distress scores inversed and doubled to get integer values only: inversed score $=2^{*}\left(-1^{*} y+\operatorname{MAX}(\mathrm{y})\right)$. The positive beta reflects improvement in voice distress scores over time. ${ }^{3}$ Linear mixed model (normal distribution).

Table 4. Time effects (pre, mid, post-treatment): linear trends estimated by (generalized) linear mixed model analysis

\begin{tabular}{|c|c|c|c|c|c|c|c|c|}
\hline \multirow[b]{2}{*}{ Parameter } & \multirow[b]{2}{*}{$\beta$} & \multirow[b]{2}{*}{ s.e. } & \multirow[b]{2}{*}{ d.f. } & \multirow[b]{2}{*}{$t$} & \multirow[b]{2}{*}{$p$} & \multicolumn{2}{|c|}{$95 \% \mathrm{Cl}$} & \multirow[b]{2}{*}{$r$} \\
\hline & & & & & & Lower & Upper & \\
\hline PSS total & -6.72 & 1.86 & 9.63 & -3.62 & .005 & -10.88 & -2.56 & .76 \\
\hline PSYRATS-AH Distress & -2.32 & .70 & 8.48 & -3.33 & .010 & -3.90 & -.73 & .75 \\
\hline PSYRATS-AH Frequency & -1.28 & .17 & 10.62 & -7.47 & $<.001$ & -1.66 & -.90 & .92 \\
\hline DASS Depression & -1.69 & 1.65 & 10.80 & -1.03 & .33 & -5.32 & 1.94 & .30 \\
\hline DASS Anxiety & -1.11 & .93 & 10.79 & -1.20 & .26 & -3.16 & .93 & .34 \\
\hline DASS Stress & -2.20 & .91 & 11.02 & -2.42 & .034 & -4.20 & -.20 & .59 \\
\hline RSES & .90 & .59 & 10.81 & 1.53 & .16 & -.40 & 2.20 & .42 \\
\hline BAVQ Malevolence ${ }^{1}$ & .18 & .08 & 33 & 2.22 & .033 & .015 & .34 & .36 \\
\hline BAVQ Omnipotence ${ }^{1}$ & .15 & .11 & 33 & 1.33 & .19 & -.08 & .37 & .23 \\
\hline
\end{tabular}

Time coded as 0,1 , 2. Effect size $r=t / \mathrm{SQRT}\left(t^{2}+\right.$ d.f.).

${ }^{1}$ Analysis on inverted values with generalized linear mixed model with negative binomial distribution and log-link because of skewed data. Coefficients in transformed space, the positive beta's represent improvement (reduction) as the scores were inverted $\left(-1^{*} y+M A X(y)\right)$. (Other variables analysed with linear mixed model (normal distribution).) PSS, Posttraumatic Symptom Scale; PSYRATS-AH, Psychotic Symptom Rating Scales - Auditory Hallucinations; DASS, Depression Anxiety and Stress Scale-21; RSES, Rosenberg Self-Esteem Scale; BVAQ, Beliefs About Voices Questionnaire-Revised; SOFAS, Social and Occupational Functioning Assessment Scale.

were analysed with generalized mixed models using a negative binomial distribution with a log-link. BAVQ malevolence showed a significant improvement over time (note that because scores were inverted, the positive beta denotes improvement), whereas BAVQ Omnipotence failed to reach significance. 


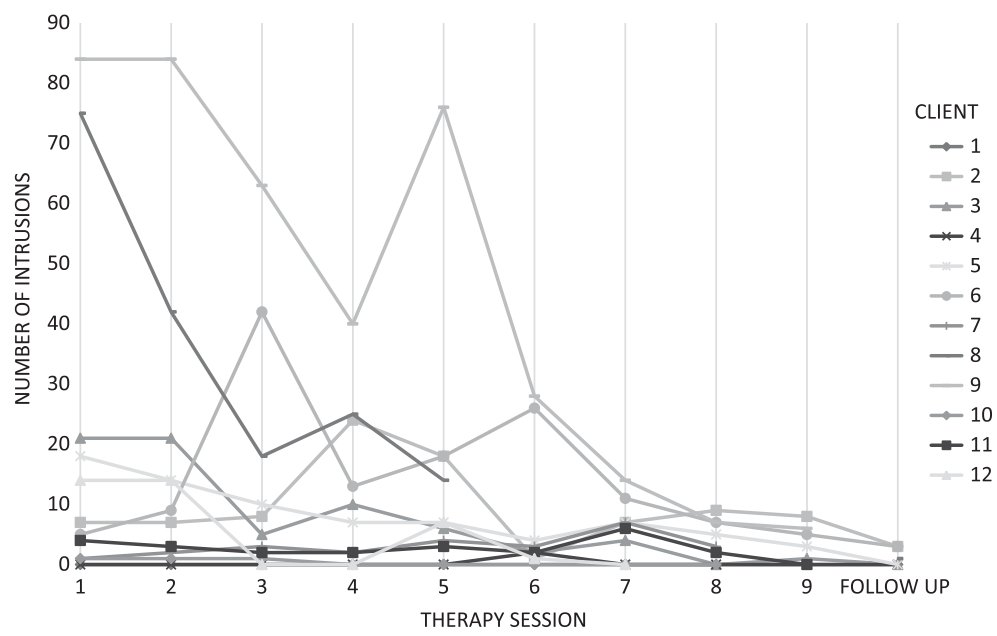

Figure 1. Number of intrusions per week recorded at sessions 1-9 (post), and at 3-month follow-up for each client.

(a)

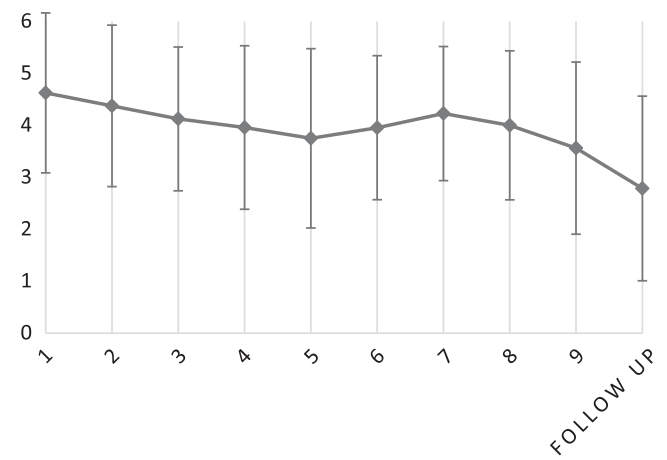

(b)

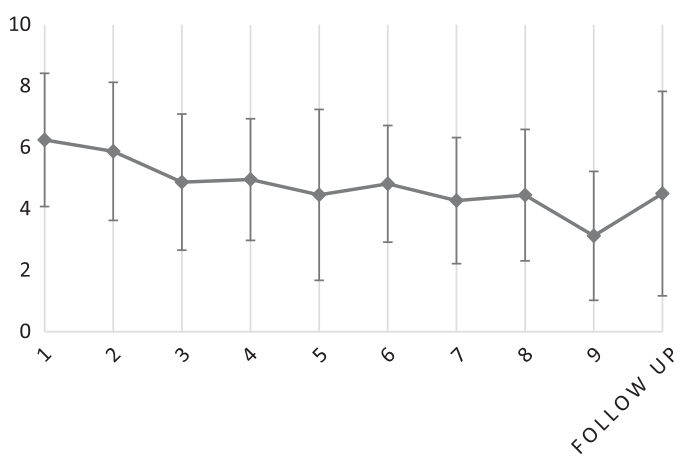

Figure 2. Group mean (and standard deviation shown as error bars) voice frequency (a) and average voice distress (b) across sessions 1-9 (post), and at 3-month follow-up.

\section{Outcomes at 3-month follow-up}

Intrusion frequency

The GLMM analysis based on a negative binomial distribution with log-link, ARMA11 structure for the repeated part, and random intercept and slope for time, showed a significant further reduction of intrusion frequency from the end of treatment to the 3-month follow-up, $t=-2.095, p=.039$.

\section{Voice distress}

The GLMM analysis of the inverted distress scores (see 'Session-by-session outcomes' section) based on a negative binomial distribution with log-link, ARMA11 structure for the repeated part, and random intercept and slope for time, showed a non-significant increase of voice distress from the end of treatment to the 3-month follow-up, $t=1.527, p=.131$. 
Voice frequency

The LMM analysis with ARMA11 structure for the repeated part, and random intercept, revealed a non-significant decrease of voice frequency from the end of the treatment until 3 months, $t=-.562, p=.58$.

\section{Qualitative client feedback}

All participants except one (participant 7) gave feedback in their post-therapy assessment session, which was recorded verbatim (see Table 6 in Supplementary Material). The following themes emerged in the feedback (the number of participants endorsing the theme in parentheses): increased compassion for me and/or my voices (5); positive change in the themes/content of my voices (5); I liked the process of ImRs therapy (4); increased understanding of my voices and trauma (3); reduced frequency and/or distress of my voices (3); reduced my PTSD symptoms (3); improved functioning and 'changed my life' (3); voices and/or PTSD symptoms made worse initially in the intervention (2); and the importance of the therapeutic relationship (2).

\section{Discussion}

The current study suggests that imagery rescripting for PTSD symptoms is generally well tolerated and can be clinically beneficial for individuals whose voice hearing is distressing. Participants not only reported a progressive reduction in their traumatic memory intrusions, but also reductions in voice frequency and distress, based on both brief weekly measures and on more extensive measures taken at pre-, mid- and post-intervention. When the brief measures were taken again at 3-months follow-up, further reductions in trauma intrusions were reported, and the reductions in voice distress and frequency were maintained. All but one participant completed the intervention, and although two clients reported an initial increase in intrusions after commencing rescripting on a new trauma, these were not long endured (lasting only 1 week), and no other adverse events were associated with the intervention.

The effects of ImRs on both trauma-related intrusions and voice frequency and distress were large and robust. Improvements on all other measures were either not significant (depression, anxiety, self-esteem, voice omnipotence, and social and occupational functioning) or where significant the effects were small (stress and voice malevolence). These outcomes suggest that the intervention primarily targeted trauma-related intrusions and that voice frequency and distress are closely associated with this phenomenon. Although it has been suggested that voices relate to the PTSD symptoms of avoidance, numbing and arousal, rather than trauma intrusions per se (Hardy et al., 2016), our clinical impression is that both constructs (voices and intrusions) improved in the same individuals in this intervention. Large-scale studies with frequent assessment intervals are necessary to investigate the temporal relationships between PTSD symptoms, voice frequency, and voice distress. It would also be interesting for such studies to investigate if there are any differences in voice reductions between people who report a direct association (i.e. hearing the voice of their perpetrator) or indirect association (i.e. thematic or affective link) between their voices and trauma. The current study only included one participant with a 'direct-only' association; however, this participant was the only participant to have stopped hearing voices by the end of the intervention (she heard one muffled sound - but not the voice of the perpetrator - at post-therapy assessment, and at 3-month follow-up she reported no hallucinatory experiences since). This finding (if replicated) could be explained by the contextual integration theory of voices (Steel, 2015; Steel et al., 2005), such that when a voice hearer constructs a complete memory/image of the traumatic event through therapeutic processes such as rescripting or prolonged exposure (PE), they no longer continue to retrieve the memory involuntarily, through intrusions such as voices. 
Significant improvements in beliefs about voice malevolence (but not voice omnipotence) were reported. Two themes that arose in the qualitative client feedback may shed light on this finding (n.b. the percentage of clients endorsing these themes may be higher as no direct questions were asked). First, five participants reported there to be a shift in the content of their voices. For most people this meant the voices being less critical and hostile. Second, three clients reported that they had an increased understanding of the link between their voices and trauma.

Two participants reported in the feedback (and can be seen in Fig. 1) that traumatic memory intrusions increased initially, and two more clients had spikes in their intrusions several sessions into therapy following the first rescript of a different traumatic memory. However, intrusions had come down for all clients by sessions 5-6. Other than this, no adverse events were reported by participants in relation to therapy. An additional interesting piece of feedback from one participant (participant 4) was it was difficult for me to reach the depth of emotion to be therapeutic because I was afraid of the voices being privy to my past trauma', which could potentially be a barrier for any trauma intervention in voice hearers that may warrant more attention by the therapist in the initial phase of therapy.

The therapist (author G.P.) had three main reflections based on her observations of the ImRs process. First, the number of sessions may need to vary depending on the severity of PTSD and number of traumas. For some participants eight sessions was more than enough (two participants finished therapy early because both participant and therapist agreed that they had met their treatment goals), while for four other participants both therapist and participant agreed that several more sessions would have been ideal. Second, the ideal length of each session would have been 90 minutes (as in the van den Berg et al. (2015) RCT of PE and EMDR), as it was difficult to complete all set agenda items in 60-minute sessions. However, lengthening the sessions to 90 minutes might pose difficulties in everyday clinical practice in some countries, when funding schemes are set up for 50-60 minutes per session. Finally, the therapist had previously used PE to treat trauma in clients with voices and/or psychosis. She felt that the ImRs process was more acceptable (and at times even enjoyable) for clients and more agreeable for the therapist also.

In the current study, only one of the 12 participants withdrew from therapy $(8.33 \%)$, which is lower than in previous PTSD in psychosis studies. Although the precision of this finding is small (given the small sample size), it may be attributable to the type of trauma therapy administered. Keen et al. (2017) reported a high drop-out rate (35.6\%) in their case-series $(n=14)$ of prolonged exposure in veterans with PTSD and psychosis. Their qualitative analysis showed that drop-out was mostly related to fear about their ability to manage distress associated with the reliving of the hot part of traumatic memories during PE. Our high retention rate may be partly because ImRs does not involve the (prolonged) reliving of the hot part of the traumatic memory.

Brand and colleagues' (2018) recent meta-analysis of PTSD interventions conducted in people with a psychotic illness found that overall PTSD symptoms were only mildly improved and that auditory hallucinations did not improve significantly. However, both clinical variables were found to have improved in the current study. This inconsistency may be explained by a number of differences between our study and previous studies. Firstly, the current study may have included more sensitive measures of voices. We examined voice frequency and distress specifically, while previous psychosis studies have more commonly reported on total scores only, which include several variables that one may not expect to change as a result of therapy, such as voice location. Secondly, ImRs as a stand-alone treatment has not previously been studied [except for a case-series $(n=4)$ of a two-session ImRs intervention in voice hearers, which also found improvements in voice distress; Ison et al., 2014]. ImRs may be more effective at treating PTSD symptoms and related voices than other types of trauma interventions because it generalizes from one memory to another related memory, which is ideal in a population such as voice hearers where the most common types of trauma are repeated, such as repeat childhood sexual abuse (Hardy et al., 2016; Sheffield et al., 2013; Trotta et al., 2015). Finally, there are also other methodological differences and/or limitations of the current study which may have impacted 
the findings, such as our transdiagnostic sample; the absence of an independent assessor (which may have positively biased the results); only one therapist (thus, results may not generalize); and the current study data are based on a single arm design with a small sample size (thus we cannot firmly establish that the treatment produced the observed changes). The last of these is important given that de Bont et al. (2016) described an RCT comparing PE, EMDR and treatment-as-usual (TAU) in people with psychosis and PTSD showed reductions in voices in all three groups over time (although they did not confirm this with statistical analyses, only that there were no differences between the three groups) and thus voice-related improvements may not be due to treatment effects in the current study. Also, given that participants were presenting for treatment at a 'voices clinic', there may have been some additional bias in expecting voice-related change. A large-scale RCT of ImRs compared with TAU and an active trauma intervention such as PE in voice hearers would help to delineate between these possible explanations and overcome the methodological limitations of the current study.

\section{Conclusions}

The findings of the current study provide initial support for the use of ImRs to be used to treat trauma and distressing voices in people with auditory hallucinations. A larger RCT of this intervention in voice hearers is now warranted.

Supplementary material. To view supplementary material for this article, please visit https://doi.org/10.1017/ S1352465819000237

Acknowledgements. We would like to thank Murdoch University and Midland HeadSpace (who partner with Perth Voices Clinic) and Maddie Graham for her research assistant work on this project.

Conflicts of interest. Georgie Paulik, Craig Steel and Arnoud Arntz have no conflicts of interest with respect to this publication.

Ethics statement. Ethical approval was obtained by the Murdoch University Human Research Ethics Committee (reference no. 2016/089), and all participants gave written informed consent for their de-identified clinical data to be published.

Financial support. This research received no specific grant from any funding agency, commercial or not-for-profit sectors.

\section{References}

Aleman, A. and Laroi, F. (2008). Hallucinations: The Science of Idiosyncratic Perception. Washington, DC: American Psychological Association.

Alliger-Horn, C., Zimmermann, P. and Mitte, K. (2015). Comparative effectiveness of IRRT and EMDR in war-traumatized German soldiers [Vergleichende Wirksamkeit von IRRT und EMDR bei kriegstraumatisierten deutschen Soldaten]. Trauma and Gewalt, 9, 204-215.

Anketell, C., Dorahy, M. J., Shannon, M., Elder, R., Hamilton, G., Corry, M., et al. (2010). An exploratory analysis of voice hearing in chronic PTSD: potential associated mechanisms. Journal of Trauma and Dissociation, 11, 93-107. doi: 10.1080/ 15299730903143600

Antony, M. M., Bieling, P. J., Cox, B. J., Enns, M. W. and Swinson, R. P. (1998). Psychometric properties of the 42-item and 21-item versions of the Depression Anxiety Stress Scales in clinical groups and a community sample. Psychological Assessment, 10, 176-181.

Arntz, A. (2012). Imagery rescripting as a therapeutic technique: review of clinical trials, basic studies, and research agenda. Journal of Experimental Psychopathology, 3, 189-208. doi: 10.5127/jep.024211

Arntz, A., Sofi, D. and van Breukelen, G. (2013). Imagery rescripting as treatment for complicated PTSD in refugees: a multiple baseline case series study. Behaviour Research and Therapy, 51, 274-283.

Arntz, A., Tiesema, M. and Kindt, M. (2007). Treatment of PTSD: a comparison of imaginal exposure with and without imagery rescripting. Journal of Behavior Therapy and Experimental Psychiatry, 38, 345-370. doi: 10.1016/j.jbtep.2007.10. 006

Arntz, A. and Weertman, A. (1999). Treatment of childhood memories: theory and practice. Behaviour Research and Therapy, 37, 715-740. doi: 10.1016/S0005-7967(98)00173-9 
Brand, R. M., McEnery, C., Rossell, S., Bendall, S. and Thomas, N. (2018). Do trauma-focused psychological interventions have an effect on psychotic symptoms? A systematic review and meta-analysis. Schizophrenia Research, 195, 13-22. doi: 10. 1016/j.schres.2017.08.037

Brewin, C. R. and Patel, T. (2010). Auditory pseudo-hallucinations in United Kingdom war veterans and civilians with posttraumatic stress disorder. Journal or Clinical Psychiatry, 71, 419-425. doi: 10.4088/JCP.09m05469blu

Carr, S. C., Hardy, A. and Fornells-Ambrojo, M. (2016). Trauma and life events checklist, version 9 (part of S. Carr's doctoral thesis, University College London).

Chadwick, P., Lees, S. and Birchwood, M. (2000). The revised Beliefs About Voices Questionnaire (BAVQ-R). British Journal of Psychiatry, 177, 229-232. doi: 10.1192/bjp.177.3.229

de Bont, P. A., van den Berg, D. P., van der Vleugel, B. M., de Roos, C., de Jongh, A., Gaag, M., et al. (2016). Prolonged exposure and EMDR for PTSD v. a PTSD waiting-list condition: effects on symptoms of psychosis, depression and social functioning in patients with chronic psychotic disorders. Psychological Medicine, 1, 1-11.

de Bont, P. A., van den Berg, D. P., van der Vleugel, B. M., de Roos, C., de Jongh, A., van der Gaag, M., et al. (2015). Predictive validity of the Trauma Screening Questionnaire in detecting posttraumatic stress disorder in patients with psychotic disorders. British Journal of Psychiatry, 206, 408-416. doi: 10.1192/bjp.bp.114.148486

Ehlers, A., Clark, D. M., Hackmann, A., McManus, F., Fennell, M., Herbert, C., et al. (2003). A randomized controlled trial of cognitive therapy, a self-help booklet, and repeated assessments as early interventions for posttraumatic stress disorder. Archives of General Psychiatry, 60, 1024-1032. doi: 10.1001/archpsyc.60.10.1024

Foa, E. B., Riggs, D. S., Dancu, C. V. and Rothbaum, B. O. (1993). Reliability and validity of a brief instrument for assessing post-traumatic stress disorder. Journal of Traumatic Stress, 6, 459-473.

Goldman, H. H., Skodol, A. E. and Lave, T. R. (1992). Revising axis V for DSM-IV: a review of measures of social functioning. American Journal of Psychiatry, 149, 1148-1156. doi: 10.1176/ajp.149.9.1148

Grunert, B. K., Weis, J. M., Smucker, M. R. and Christianson, H. F. (2007). Imagery rescripting and reprocessing therapy after failed prolonged exposure for psot-traumatic stress disorder following industrial injury. Journal of Behavior Therapy and Experimental Psychiatry, 38, 317-328. doi: 10.1016/j.jbtep.2007.10.005

Hackman, A. (2011). Imagery rescripting in posttraumatic stress disorder. Cognitive and Behavioral Practice, 18, 424-432.

Haddock, G., McCarron, J., Tarrier, N. and Faragher, E. B. (1999). Scales to measure dimensions of hallucinations and delusions: the psychotic symptoms rating scales (PSYRATS). Psychological Medicine, 29, 879-889.

Hardy, A. (2017). Pathways from trauma to psychotic experiences: a theoretically informed model of posttraumatic stress in psychosis. Frontiers in Psychology, 8, 697-717. doi: 10.3389/fpsyg.2017.00697

Hardy, A., Emsley, R., Freeman, D., Bebbington, P., Garety, P. A., Kuipers, E. E., et al. (2016). Psychological mechanisms mediating effects between trauma and psychotic symptoms: the role of affect regulation, intrusive trauma memory, beliefs, and depression. Schizophrenia Bulletin, 42(suppl), S34-S43. doi: 10.1093/schbul/sbv175

Hardy, A., Fowler, D., Freeman, D., Smith, B., Steel, C., Evans, J., et al. (2005). Trauma and hallucinatory experience in psychosis. Journal of Nervous Mental Disorders, 193, 501-507. doi: 10.1097/01.nmd.0000172480.56308.21

Henry, J. D. and Crawford, J. R. (2005). The short-form version of the Depression Anxiety Stress Scales (DASS-21): construct validity and normative data in a large non-clinical sample. British Journal of Clinical Psychology, 44, 227-239.

Hilsenroth, M. J., Ackerman, S. J., Blagys, M. D., Baumann, B. D., Baity, M. R., Smith, S. R., et al. (2000). Reliability and validity of DSM-IV axis V. American Journal of Psychiatry, 157, 1858-1863. doi: 10.1176/appi.ajp.157.11.1858

Ison, R., Medoro, L., Keen, N. and Kuipers, E. (2014). The use of rescripting imagery for people with psychosis who hear voices. Behavioural and Cognitive Psychotherapy, 42, 129-142. doi: 10.1017/s135246581300057x

Keen, N., Hunter, E. C. M. and Peters, E. (2017). Integrated trauma-focused cognitive-behavioural therapy for post-traumatic stress and psychotic symptoms: a case-series study using imaginal reprocessing strategies. Frontiers in Psychiatry, 8, 92 . doi: 10. 3389/fpsyt.2017.00092

Lovibond, S. H. and Lovibond, P. F. (1995). Manual for the Depression Anxiety Stress Scales (2nd edn). Sydney, Australia: Psychology Foundation of Australia.

McCarthy-Jones, S. and Longden, E. (2015). Auditory verbal hallucinations in schizophrenia and post-traumatic stress disorder: common phenomenology, common cause, common interventions? Frontiers in Psychology, 6, 1071. doi: 10.3389/fpsyg.2015.01071

McCarthy-Jones, S., Smailes, D., Corvin, A., Gill, M., Morris, D. W., Dinan, T. G., et al. (2017). Occurrence and co-occurrence of hallucinations by modality in schizophrenia-spectrum disorders. Psychiatry Research, 252, 154-160.

Morina, N., Lancee, J. and Arntz, A. (2017). Imagery rescripting as a clinical intervention for aversive memories: a meta-analysis. Journal of Behavior Therapy and Experimental Psychiatry, 55, 6-15.

Rosenberg, M. (1965). Society and the Adolescent Self-Image. Princeton, NJ: Princeton University Press.

Sheffield, J. M., Williams, L. E., Blackford, J. U. and Heckers, S. (2013). Childhood sexual abuse increases risk of auditory hallucinations in psychotic disorders. Comprehensive Psychiatry, 54, 1098-1104. doi: 10.1016/j.comppsych.2013.05.013

Smucker, M. R., Dancu, C., Foa, E. B. and Niederee, J. L. (1995). Imagery rescripting: a new treatment for survivors of childhood sexual abuse suffering from posttraumatic stress. Journal of Cognitive Psychotherapy, 9, 3-17. 
Steel, C. (2015). Hallucinations as a trauma-based memory: Implications for psychological interventions. Frontiers in Psychology, 6, 1262. doi: 10.3389/fpsyg.2015.01262

Steel, C., Fowler, D. and Holmes, E. A. (2005). Traumatic intrusions in psychosis: an information processing account. Behavioural Cognitive Psychotherapy, 33, 139-152. doi: 10.1017/S1352465804001924

Steel, C., Hardy, A., Smith, B., Wykes, T., Rose, S., Enright, S., et al. (2017). Cognitive-behaviour therapy for post-traumatic stress in schizophrenia. A randomized controlled trial. Psychological Medicine, 47, 43-51. doi: 10.1017/S0033291716002117

Trotta, A., Murray, R. M. and Fisher, H. L. (2015). The impact of childhood adversity on the persistence of psychotic symptoms: a systematic review and meta-analysis. Psychological Medicine, 45, 2481-2498. doi: 10.1017/S0033291715000574

van den Berg, D. P. G., de Bont, P. A., van der Vleugel, B. M., de Roos, C., de Jongh, A., van Minnen, A., et al. (2015). Prolonged exposure vs eye movement desensitization and reprocessing vs waiting list for posttraumatic stress disorder in patients with a psychotic disorder: a randomized clinical trial. JAMA Psychiatry, 72, 259-267. doi: 10.1001/jamapsychiatry. 2014.2637

Ventura, M. A., Green, M. F., Shaner, A. and Liberman, R. P. (1993). Training and quality assurance with the brief psychiatric rating scale: 'the drift buster'. International Journal of Methods in Psychiatric Research, 3, 221-244.

Woodward, T. S., Jung, K., Hwang, H., Yin, J., Taylor, L., Menon, M., et al. (2014). Symptom dimensions of the psychotic symptom rating scales in psychosis: a multisite study. Schizophrenia Bulletin, 40, 265-274.

Cite this article: Paulik G, Steel C, and Arntz A (2019). Imagery rescripting for the treatment of trauma in voice hearers: a case series. Behavioural and Cognitive Psychotherapy 47, 709-725. https://doi.org/10.1017/S1352465819000237 